\title{
Predicting movie grosses: Winners and losers, blockbusters and sleepers
}

\author{
By Jeffrey S. Simonoff and Ilana R. Sparrow
}

\section{Introduction}

The movie industry is a business with a high profile, and a highly variable revenue stream. In 1998, moviegoers spent $\$ 6.88$ billion at the U.S. box office alone. A single movie can be the difference between millions of dollars of profits or losses for a studio in a given year. It's not surprising, therefore, that movie studios are intensely interested in predicting revenues from movies; the popular nature of the product results in great interest in gross revenues from the general public as well.

In this article we examine the question of predicting movie grosses from generally available information (we will focus mostly on U.S. domestic gross, but will also examine foreign grosses to a lesser extent). The first version of this question relates to predictions prior to a movie's release, perhaps relatively early in production. How accurately can a studio predict the revenues for a movie before it opens? With some actors receiving as much as $\$ 20$ million per picture (plus a percentage of the gross revenues), producers obviously feel that star power leads to profit, but is that really true? Are certain types of movies more or less likely to be moneymakers? Do big budget movies make more money?

A different version of the prediction question shifts the time frame to immediately after release. The opening weekend of a movie's release typically accounts for $25 \%$ of the total domestic box office gross, so we would expect that the opening weekend's grosses would be highly predictive for total gross. This, however, ignores the different release patterns of movies (some movies open on thousands of screens in the first 
weekend, others build slowly into wide release, and others never show on more than a few screens). Further, do reviews by prominent critics have an effect on attendance?

Sometimes events long after a movie's release can impact revenues. The most obvious of such events is when a movie earns awards, such as Academy Awards (or nominations). Do such awards provide a boost to revenues?

\section{The data}

The analyses presented here are based on new movies released in the United States during calendar year 1998 for which relevant business information was available on the Internet Movie Database (WwW.imdb.com . Movies that opened on a limited number of screens late in 1997 (in order to be eligible for awards given in 1998), but then opened to wide release in 1998 are included in the sample; this includes movies such as Good Will Hunting and Wag the Dog. Similarly, movies that opened on a limited number of screens late in 1998 and then opened to wide release in 1999 are not included; examples of such films include Shakespeare in Love and La Vita è Bella (Life is Beautiful). This yields a total of 311 films.

The response of interest here is the total U.S. domestic gross revenue for each film. Cursory examination of this variable shows that it is long right-tailed (ranging from a low of \$349 for Biker Dreams to roughly \$216 million for Saving Private Ryan), so the logarithm of domestic gross will be used as the variable we attempt to explain in the article. The predictor variables we consider include the following, versions of which have been considered in previous examinations of movie revenues and profits (although, to our knowledge, all have never been considered before in the same study): 
1. The genre of the film, a categorical variable classifying the film as Action, Children's, Comedy, Documentary, Drama, Horror, Science Fiction, or Thriller. Genres were obtained from the Videolog catalog published by Blockbuster Video. For the few movies that were not in the catalog, genres were obtained from Variety magazine and WWW.reel.com a web site devoted to consumer purchase of movies.

2. The Motion Picture Association of America (MPAA) rating of the film, one of the ratings $\mathrm{G}$ (general audiences), PG (parental guidance suggested), PG-13 (possibly unsuitable for children less than 13 years of age), $\mathrm{R}$ (children not admitted unless accompanied by an adult), NC-17 (no one under 17 admitted), and U (unrated).

3. The origin country of the movie, classified as U.S., English-speaking (but not U.S.), or non-English-speaking.

4. Two variables attempting to measure "star power." The first is the number of actors or actresses appearing in the movie who were listed in Entertainment Weekly's lists of the 25 Best Actors (August 7, 1998) and the 25 Best Actresses (November 20, 1998) of the 1990s. The second is the number of actors or actresses appearing in the movie who were among the top 20 actors and top 20 actresses in average box office gross per movie in their careers, according to The Movie Times web site. The latter variable is as of the beginning of the 1998 movie season, and only includes actors and actresses who had appeared in at least 10 movies at that time.

5. The production budget of the film (in millions of dollars). Cursory examination of this variable shows that it is also long right-tailed, so the logarithm of the budget will be used.

6. Whether or not the movie was a sequel to an earlier movie. 
7. Three indicator variables identifying whether or not the movie was released before a holiday weekend (President's Day, Memorial Day, Independence Day, Labor Day, Thanksgiving, or the Christmas season), was released during the Christmas season (December 18-31), and/or was released during the summer season (Memorial Day through Labor Day).

8. The number of screens for the film's first weekend of general release. In addition to the movies mentioned earlier that opened to limited release in late 1997, some movies first opened to limited release in 1998, followed by wider release later that year (examples of such films are The Boxer and Bulworth). In all such cases, figures for the first weekend of wider (general) release are used. Cursory examination of this variable shows that it is also long right-tailed, so the logarithm of opening screens will be used.

9. The gross revenues (in millions of dollars) for the film's first weekend of general release. Cursory examination of this variable shows that it is also long right-tailed, so the logarithm of first weekend gross will be used.

10. The rating of the movie (from zero to four stars) given by Roger Ebert, the wellknown film critic from the Chicago Sun-Times, assuming Ebert reviewed the movie.

11. Academy Award (Oscar®) nominations and wins for the film. We restrict ourselves to the major categories of Best Picture, Best Director, Best Actor, Best Actress, Best Supporting Actor, and Best Supporting Actress, as these are the categories of greatest interest to the general public. Since we are examining gross theatre revenues, we are only interested in nominations and wins for movies that are still in release at the time of the nominations. 


\section{Prediction of revenues prior to release}

We first examine prediction of movie grosses based on information available prior to release, perhaps early in production. Figure 1 gives side-by-side boxplots of total domestic gross separated by the level of different variables available before the release of a film (the width of the boxes is proportional to the square root of the number of observations in that group, so relative frequencies of different types of movies can be read from the plots as well). There are apparent differences in grosses using some of these variables. For example, the genre of the movie is predictive for grosses, with certain genres (Action, Children's, Horror, and Science Fiction) noticeably higher in revenues in general. Interestingly, there seems to be an inverse relationship between the occurrence of a genre and its revenue production, with the most popular types (comedies and dramas) performing relatively poorly at the box office. The relationship between grosses and MPAA rating is similar. As the rating becomes more "mature" from G to PG to PG-13 to $\mathrm{R}$, more movies are made, typically making less money (of course, there is a connection with the Genre results here, as all but one children's movie is rated G or PG, while more than two-thirds of comedies and dramas are rated $\mathrm{R}, \mathrm{NC}-17$, or $\mathrm{U}$ ).

This effect can, in part, be explained by the success of well-targeted films that fit certain defined market segments. In the case of ratings, G, PG and PG-13 movies are generally targeting children and/or teens. Similarly, certain genres are usually geared toward a narrow market segment (e.g., horror movies are often made with the teen audience in mind). While studios may well want to produce more films in lucrative genres such as Action and Science Fiction, the barriers to entry for such films are 
prohibitively high - budgets can easily run from $\$ 70$ to over $\$ 100$ million with another \$30-40 million or more for advertising and marketing. By contrast, the average cost to make and market a studio film in 1999 was considerably less at \$87 million.

The high revenue of children's movies is somewhat illusory. Children's movies are actually composed of two very different kinds of films (live-action and animated) and are almost always rated $\mathrm{G}$ or PG. High revenues come from the animated films, which have long been considered to be one of the most profitable genres in the business (especially if the picture is by Disney). Live-action children's films, on the other hand, perform far worse than animated films (in 1998 the median total domestic gross for Grated live-action films was roughly $\$ 10$ million, while that for G-rated animated films was more than $\$ 100$ million). The surprise successes of 1990's Home Alone and 1993's Free Willy notwithstanding, live-action children's films are often money-losers at the box office, and consequently, studios have scaled back their production of such films.

While Disney has long dominated the animated film market, recent successful films from studios such as DreamWorks SKG (Antz, The Prince of Egypt), and films based on television shows (Doug's $1^{\text {st }}$ Movie, Pokémon the First Movie), suggests that the lucrative animation market might get more attention in the future. Still, the economics of producing and releasing animated films are prohibitive. An animated movie often takes four years or more to produce (quite long by Hollywood standards) and involves hundreds of technically skilled artists and programmers who are not part of the studio's usual employees, and therefore need to be hired on as contractors. The market for such highly skilled people is dominated by a few top niche firms (such as Pixar and Industrial Light \& Magic). Pixar, for example, is already in an exclusive relationship with Disney. 
Furthermore, as Dade Hayes, a Variety reporter based in Los Angeles, points out, "the marketing of such films requires a highly developed infrastructure of business partners such as toy makers and fast food chains, which many studios do not already have in place."

Studios make fewer G and PG films since they are skewed to a narrower market, while PG-13 and R films have a much larger potential audience. The PG-13 rating is quite desirable, as it can pull in both adults and children, and excludes virtually no one.

Other relationships are as would be expected. Movies made in English-speaking countries (including the U.S.) make more money (note that 35 of the 39 non-English movies are rated $\mathrm{R}$ or $\mathrm{U}$, so there is a rating effect here as well). Even with a PG-13 rating, non-English speaking movies have to overcome one of the toughest obstacles any movie could have, that of finding U.S. distribution. Non-English speaking movies are a risky endeavor for most distributors, as audiences are notorious in their dislike for subtitles. The market for foreign films is much smaller than that for U.S. films, since its core market is restricted to an older, college-educated segment. Movies with more of the "best" actors and top dollar actors make more money, an encouraging result for believers in "star power" (although obviously many movies with no big-name actors did very well at the box office). Sequels generally perform better than non-sequels, presumably reflecting the success of the earlier film(s). It should be noted, however, that 10 of the 13 sequels came from the action, children's, horror, and science fiction genres, the highest revenue groups. The three timing variables (holiday, summer, or Christmas release) apparently have less relation to revenues, although in all three cases the third quartile of grosses is noticeably higher for the seasonal releases than the non-seasonal releases. 
Movies that are expected to appeal to the youth market are usually released during the summer and holidays in hopes of getting high initial and repeat business, with other films moved to other times because of limited screen availability and the desire to avoid direct competition with a potential blockbuster.

These scheduling issues put a natural limit on the number of big budget films (with potentially high revenue but also high risk) studios will release in any given year. Release dates are one of the most important factors in determining the success of a film. It is common practice in Hollywood to stake out a particular release date for a major film over a year in advance and to leak the information to the trades in the hopes of scaring off the competition. In general, it is unlikely to find two major blockbuster movies going head-to-head on one weekend. Since there are a limited number of screens and weekends, some films have been held back an entire season and marketing strategies rethought, simply because a prime release date was already claimed by a rival studio. Interestingly, this is as equally true of small budget pictures as of the typical blockbuster event film.

The graphs of Figure 1 identify the effects of individual variables. To better predict gross revenues we use linear regression models that incorporate some or all of the variables at the same time. As was noted earlier, we use regression modeling to model the logarithm (base 10) of the total gross. With a combination of categorical and continuous predictors, the regression models are analysis of covariance models, which can be fit using indicator variables identifying all but one of the groups (for each variable), if software that fits such models is unavailable. Table 1 summarizes the fit of our best prerelease model. The variables in the model include Genre, MPAA rating, Number of best 
actors, Number of top dollar actors, and whether or not the movie was a Summer release. Given these variables, the other potential predictors do not add significantly to the fit. The table gives effects for the categorical predictors, along with the associated partial Ftests of significance and p-values, coefficients for the continuous predictors, along with associated F-tests of significance and p-values (F-tests are given, rather than the equivalent $\mathrm{t}$-tests, to facilitate comparison with the categorical predictors), the $\mathrm{R}^{2}$ for the model, and $s$, the standard error of the estimate. Note that the coefficients of the categorical predictors Genre, MPAA rating and Summer release are constrained to sum to zero across all of the categories.

Predictions from the model are made by summing the constant, the appropriate effects for Genre, MPAA rating, and Summer release, and the products of the coefficients for the actors with the actual numbers for the film. For example, Dancing at Lughnasa was a PG-rated drama not released during the summer with one best actor and no top dollar actors, so its predicted log gross is .394-.408+.380-.150+(1)(.400)+(0)(.712)=.616, and its predicted gross is $10^{.616}=\$ 4.13$ million .

The coefficients in Table 1 (which take all other variables in the model into account) correspond closely to the effects seen in the boxplots of Figure 1. That is, while action, horror and science fiction movies generate more revenue than average, dramas and (especially) documentaries do worse than average. The poorer performance of movies rated $\mathrm{R}$ and $\mathrm{NC}-17$ is also clear, as is the benefit of a summer release. The two strongest effects (given all else in the model) are the "star power" variables, with each additional cast member from the Best actors list multiplying estimated gross revenue by roughly $2.5\left(10^{.4}=2.51\right)$ and each additional cast member from the Top dollar actors list 
multiplying it by more than 5 (holding all else fixed). Note, by the way, that since these actors no doubt are paid high salaries, these increased revenues do not necessarily translate into increased profits.

Overall the model explains $44.6 \%$ of the variability in log domestic revenue. The standard error of the regression is .982 , which indicates the weakness of the model for predicting grosses. A rough $95 \%$ prediction interval for logged domestic gross is $\pm(2)(.982)=1.964$, or roughly \pm 2 . This means that predictions of total grosses for an individual movie can be expected to be off by as much as a multiplicative factor of 100 high or low.

Table 2 summarizes observed and predicted total grosses (in millions of dollars) for selected 1998 movies that illustrate the properties of the model. Predictions based on the model in this section are given under Pre-release model (the other two models are discussed in later sections). The grosses of Air Bud (a G-rated children's movie released during the summer) and Stepmom (a PG-13-rated drama co-starring Julia Roberts, Susan Sarandon, and Ed Harris) are well predicted by the model. The model is less successful for the other films in the table. It is clear that the model seriously underestimates the grosses of big-budget films like Godzilla and Saving Private Ryan. The tremendous success of two of the sleeper films of 1998, Good Will Hunting (an R-rated drama costarring Robin Williams) and There's Something About Mary (an R-rated summer comedy), is completely missed by this model using pre-release properties (which can be viewed as precisely what made them sleepers). The PG-rated action film 3 Ninjas was expected to be a $\$ 10$ million revenue producer, but failed miserably. This might be an example of going to the well (at least) once too often, as this was the fourth movie in the 
Ninjas series (the studio seems to have had a hint about this, as the movie only opened on 120 screens its first weekend and was pulled from theatres after two weeks). The poor predictions for The Horse Whisperer and Hurlyburly are also interesting. The Horse Whisperer was a PG-13-rated drama without any cast members on the best or top dollar actors lists, but this ignores the presence of Robert Redford as actor and director, which no doubt increased attendance dramatically. The film was also based on a best-selling novel and had a large built-in audience, a fact that our model does not take into account. Hurlyburly, on the other hand, co-starred Sean Penn, Kevin Spacey, and Meg Ryan, but did very poorly at the box office, presumably because of its disturbing character (a good deal of drug use, strong language, and sexual material). Hurlyburly was also subject to mixed reviews, a very limited audience, and limited engagement. Additionally, while the film had several Hollywood stars in it, they functioned as an ensemble cast, apparently negating the pull of star power in attracting an audience.

The failure of the model for the big-budget movies mentioned earlier begs the question of why the (logarithm) of the budget is not used in the model. As Figure 2 shows, logged gross and logged budget are definitely positively related. Unfortunately, this relationship may not be what it seems. First, most of the budget numbers (almost 60\%) are not available. More importantly, the numbers that are available are suspect at best. Budget figures are notoriously difficult to obtain. In addition, the production budget only represents part of the cost of making a movie (it ignores, for example, advertising and distribution costs). Even if a number is available, it is very difficult to evaluate it, as the specifics surrounding the financing of a given film are cloaked in secrecy. For example, a budget figure may be deceptively low given the star and director power 
(Saving Private Ryan, with a $\$ 65$ million budget, is a good example of this), because the director and star waived their normal salary requirements for a participation in the film's gross receipts. Unfortunately, it is impossible to find out the exact amount of "back-end" paid out under such circumstances. It is equally difficult to know whether or not a quoted budget contains the advertising and distribution costs or not. Leonard Klady, formerly a Variety entertainment reporter, points out that "it is often said that the majors lie down and the indies lie up. People spin the figures." Advertising budgets are typically $\$ 20-30$ million for a large-scale studio release, but the addition of tie-in partners and other promotional items makes it very difficult to know how much is actually being spent by the studio itself to market the film. Thus, even though studio heads would know the budgets for their own films, we cannot build a prediction model based on budgets. For this reason, we will not consider the budget as a predictor (for the same reason, we are focusing on revenues here, rather than the perhaps more interesting profits or returns on investment).

\section{Prediction of revenues after the first weekend of release}

The performance of a movie during its first weekend of release is watched closely by people both inside and outside the film industry. Klady describes a film's opening weekend as "a bellwether," adding that "by and large, most films tend to open at their height." It is on the strength of the opening weekend of general release that all major decisions pertaining to a film's ultimate financial destiny are made. Since competition for movie screens is fierce, movie theater owners do not want to spend more than the contractually obligatory two weeks on a film that doesn't have "legs." Should a film lose 
its theatrical berth so quickly, chances are slim that it will have significant play internationally (if at all), and it is unlikely that it will make it to pay-per-view, cable or network television. This all but guarantees that ancillary revenue streams will dry up, making a positive return on investment very difficult to achieve, as ancillary deals are predicated on domestic box office gross. Movie theater owners often make the decision to keep a film running based on the strength of its opening weekend.

Of course, there are certain circumstances where a film that does poorly at the outset may yet be saved. Perhaps, for example, the studio will throw more money into the ongoing promotional campaign targeting a different audience than was targeted up front. Tim Noonan, a business development executive formerly at New Line Cinema, describes the first weekend gross as "predictive of what the movie will do overall...it's a signal to us to extract the most value as an asset. Can you do more with it? Take it wider?" The first weekend gross helps a studio learn if the marketing strategy was deadon or wrong, and if wrong, if it is salvageable. A recent example Noonan cited was the case of Drop Dead Gorgeous, a 1999 New Line release that was given a national wide release but performed disappointingly in its opening weekend. Looking at its latest market research results, New Line discovered that while Middle America didn't get the movie, a more narrow demographic — sophisticated, gay urbanites — loved it. As a result, the studio reevaluated Drop Dead Gorgeous' positioning and decided to pull all national ad campaigns and pour the money into targeted regional efforts instead. This quick shift in strategy managed to keep the film in theaters longer, giving it a better shot at long-term profitability. 
Clearly it is believed that the first weekend's performance is highly predictive for ultimate performance, but is this actually true? Figure 3 suggests that it is, but only to a certain extent. While the logged first weekend gross is highly correlated with logged total domestic gross $(r=.93)$, it is apparent that the strength of the relationship is different for movies with lower grosses versus movies with higher grosses.

A model using Genre, Logged first weekend gross, and Logged number of opening screens as predictors apparently fits the data very well $\left(\mathrm{R}^{2}=92.0 \%\right)$, but this result is illusory. Figure 4 is a plot of the standardized residuals from this fit versus logged opening screens. The variability of the residuals decreases abruptly when the number of opening screens exceeds 10 (logged opening screens exceeding one); that is, it is considerably harder to predict total gross from first weekend gross for movies in very limited initial release than for those in even limited release (recall that this variable refers to the number of screens in the first week of wide release of a movie, if the movie was released widely). There is enormous variability in the way small-release movies are screened and marketed. For the most part, the kinds of movies that receive an initial and/or full release of less than ten screens are niche market pictures, such as foreign films, small independent productions and documentaries, and often get released in specific art-house theaters in major markets only. Additionally, the length of time a given film may play can vary widely. That time frame is dependent on factors as diverse as competition for screens, film festival awards, word of mouth, and reviews. Overall, these movies generally rely most heavily on word of mouth and reviews to keep them in theaters for any appreciable length of time. 
In some cases, depending on the target audience, studios sometimes take advantage of this fact with a kind of marketing strategy known as "platforming." In such a case, a film is intentionally opened up slowly, in stages, starting in just a few key cities. This is generally employed when the film's primary demographic is more literate, highbrow adults.

Figure 5 repeats Figure 3, identifying movies by whether or not they opened on more than 10 screens. It is apparent that the relationships in the plot are different for the two groups, in terms of both slope and variability. For this reason, the movies will be separated into two groups: those that open on 10 screens or less (116 films), and those that open on more than 10 screens (192 films) (the number of opening screens was unavailable for three films).

Table 3 summarizes the results for regression models predicting log gross from information available after the first weekend. Table 3(a) refers to fitting for the movies opening on ten or fewer screens. The chosen model is based on only Logged first weekend gross and Logged opening screens, with an $\mathrm{R}^{2}$ of $73.5 \%$ (adding a possible effect of Christmas release adds only $0.8 \%$ to the $\mathrm{R}^{2}$ ); given these two variables, none of the other variables add significantly to the model. The coefficients for the model are nicely intuitive. Holding the number of opening screens fixed, multiplying the first weekend's gross by 10 is associated with multiplying the total gross by $10^{1.8}=64.3$. On the other hand, holding the first weekend's gross fixed and multiplying the number of screens by 10 (resulting in a $90 \%$ lower per screen average revenue) is associated with a decrease in the total gross by $71 \%\left(10^{-53}=.29\right)$. The standard error of the regression estimate $s=.544$ implies that predictions can be expected to typically be off by no more 
than a multiplicative factor of roughly 10. This is obviously much improved over the factor of 100 possible before the opening weekend, especially since roughly two-thirds of these movies have total grosses less than $\$ 500,000$ (so in absolute terms the predictions are off by no more than a few million dollars).

Figure 6 is a plot of the standardized residuals versus the fitted values for this model. There is a bit of nonconstant variance in the plot, which comes from the constraint that the total gross revenue cannot be less than the first weekend's gross (many of these movies were only in release for one or two weeks, so this is a meaningful constraint). There are three somewhat unusual movies, which are labeled in the plot: Vietnam Long Time Coming, which performed a bit better than expected, and Un air de famille and Lawn Dogs, which performed worse than expected.

The situation is better for the movies released on more than 10 opening screens. Table 3(b) summarizes the results of fitting. The chosen model is based on Genre, Logged first weekend gross, and Logged opening screens, with an $\mathrm{R}^{2}$ of $96.6 \%$; given these variables, none of the other variables add significantly to the model. The coefficients for the two continuous predictors are similar to those for the movies in very limited opening release. Holding the number of opening screens fixed, multiplying the first weekend's gross by 10 is associated with multiplying the total gross by $10^{1.53}=33.5$, while holding the first weekend's gross fixed and multiplying the number of screens by 10 (resulting in a 90\% lower per screen average revenue) is associated with a decrease in the total gross by $75 \%\left(10^{-.6}=.25\right)$. Note that the effects for different genres are very different from the marginal relationships shown in Figure 1. This is because most of the patterns noted earlier (e.g., the large revenues for horror films) are now explained by the 
first weekend statistics. The coefficients do show that, for example, children's movies do noticeably better than first weekend results would suggest $(30 \%$ better given the first weekend numbers, since $10^{114}=1.3$ ), suggesting that they build their box office slowly, while horror films drop off more quickly from the first weekend, finishing $20 \%$ lower given the first weekend numbers. Richard Natale, in a June 23, 1998 Los Angeles Times article, reports that a 35\% drop in attendance in the second week of release is considered normal for a film targeted to the adult audience, while a horror movie may drop off by $50 \%$ in its second week of release because the teen audience that tends to go to these films prefers to see a movie as soon as it opens.

The excellent predictive power of the model is obvious from the standard error of the estimate, $s=.17$, as it implies that predictions can be expected to typically be accurate within a multiplicative factor of roughly two. Thus, for the typical movie at the neighborhood multiplex, knowing the first weekend results provides an excellent forecast for total revenues.

Note that for both regression models summarized in Table 3, once the first weekend statistics are available, previously useful information becomes superfluous. That is, any benefits of star power or a child-friendly MPAA rating in predicting total gross are accounted for by the first weekend results, and don't add any further predictive power.

A return to Table 2 shows the usefulness of the added information by examining the entries under First weekend model. The ultimately surprisingly poor showings of 3 Ninjas and Hurlyburly, and surprisingly good performances of The Horse Whisperer and Saving Private Ryan, weren't surprising at all after the first weekend. Good Will Hunting and There's Something About Mary are better predicted than before, but the predictions 
are still considerably too low. Interestingly, Godzilla now shows up as a severe underachiever, which makes sense. It opened to very large crowds initially, but horrible reviews and word-of-mouth ultimately made it one of the biggest disappointments of 1998 (even though it was the tenth-highest domestic revenue producer).

It is worth commenting here on the absence of one seemingly obvious factor, reviews. Roger Ebert reviewed roughly $70 \%$ of the movies released in 1998. It is difficult to incorporate his reviews (by simply dropping the cases with missing data, or more complex imputation schemes) because the movies he reviewed are certainly not a random sample of those released. Ebert was presumably more likely to review movies opening on more screens, and more likely to review movies expected to be of higher quality (even if they had only limited release). It would be a good idea to measure critical opinion using some sort of consensus review in future work.

\section{Do Oscars matter?}

The Academy Awards (known as Oscars) are the most sought after prizes in the film industry. Every year movie studios spend tens of millions of dollars promoting certain films for Oscar consideration, such as in trade advertising (some studios have been rumored to spend as much on trade advertising vying for Academy recognition for a film as they have on consumer campaigns for the film). Since the nominations occur after the first weekend of release, an interesting question is whether receiving nominations or awards (particularly in the major categories) provides a boost to revenues, given the revenues already earned. This question can be examined from a statistical point of view 
by seeing whether variables representing Oscar nominations and awards provide additional power for predicting gross revenue.

Table 4 summarizes the results of adding the number of major Oscar nominations to the regression models of Table 3, for films opening on no more than 10 screens (Table 4(a)) and on more than 10 screens (Table 4(b)). In each case the number of Oscars actually won does not add appreciable predictive power to the model (only one film opening on 10 or fewer screens won an Oscar in the major categories, and including Oscars won as a predictor for movies opening on more than 10 screens adds less than $0.1 \%$ to the $\mathrm{R}^{2}$ ). The nomination effect is appreciable for both classes of movies. For movies opening on no more than 10 screens, each additional Oscar nomination is associated with multiplying the expected gross by roughly 2.5 (holding all else fixed), while for movies opening on more than 10 screens, each Oscar nomination is associated with increasing the expected gross by roughly $30 \%$.

The overall fit of the models improved only slightly, since only ten of 311 movies received nominations in the major categories while still in release. Figure 7 brings this out. The figure gives scatter plots of the absolute standardized residuals from the models that do not use Oscar nominations as a predictor versus those from the models that do, for movies released on ten or fewer screens (a) and those released on more than ten screens (b). Note that the two versions of the models are not identical, since the models for movies released on more than ten screens include Genre as an effect. For most movies the residuals are close (resulting in the diagonal line in each plot); these, of course correspond to movies that did not receive any nominations. This can be seen in Table 2 also, as the predicted grosses for all of the movies except Good Will Hunting and Saving 
Private Ryan (the two movies in the list with nominations) are very similar in the final two columns.

Any observations in the plots below the diagonal line correspond to movies where knowledge of Oscar nomination(s) improved prediction. Since the effect of Oscar nomination on the model is to increase predicted gross, these are films that benefited from being nominated. Figure 4(a) identifies the five limited release movies that received nominations, all of which earned 2.7-10 times as much as would have been predicted without using Oscar nominations.

In Figure 4(b), four of the Oscar nominated-movies benefited from the nomination(s), with five-time nominee Good Will Hunting earning more than three times the total gross predicted without using nominations (as given in Table 2, where the prediction based on using nominations is seen to be quite accurate). On the other hand, Saving Private Ryan seems to have suffered from Oscar nomination. This is not correct; rather, the film did not receive the benefit from its three Oscar nominations that would be expected, as can be seen in Table 2, where the predicted gross based on using nominations is far too high. What has happened here? Saving Private Ryan, which was released nine months before the Oscars, was the only one of the ten movies with major nominations not to have been released less than four months before the nominations, when the film could still benefit from the Oscar publicity. Thus, while movies released late in the year (including those in limited release in December followed by wide release in January, where the initial release is actually referred to as an "Oscar Engagement") do seem to receive an Oscar boost, films nominated many months before do not. Of course, these data do not reflect that Oscar nominations can bring the film back to theatrical 
release if it has left the theaters. This kind of exposure also helps the film increase revenues internationally, as the Oscars would most likely be held when the film is still in release abroad. Ultimately, it helps the film throughout all of its ancillary markets. In the case of Saving Private Ryan, while the film did not receive the same Oscar boost as the other Best Picture nominees, it ended up the highest grossing film of 1998, and went on to do extremely well internationally also.

\section{Using the models to predict new movie grosses}

Although the implications of the models fit in the previous sections as descriptions of the revenue process are interesting, the real usefulness of such models to a producer or studio is in the prediction of future revenues for new projects. In order to investigate this we applied our final model (using the coefficients derived from 1998 data) to the 24 movies put in wide release in the first two months of 1999. This includes five films put in Oscar Engagement release in late 1998 that were nominated shortly thereafter for major Academy Awards (A Civil Action, La Vita è Bella (Life is Beautiful), Shakespeare in Love, A Simple Plan, and The Thin Red Line).

Figure 8 gives predictions and prediction intervals for the total domestic gross for the 1999 films, along with the observed values. In 21 of the 24 intervals, the observed gross is well within the prediction interval, and many predicted values are very close to the observed values. The observed grosses for Waking Ned Devine, and to a greater extent, La Vita è Bella and Shakespeare in Love, are higher than expected. All three films opened in general release on fewer than 650 screens, gradually widening release to (in the case of Shakespeare in Love) over 2000 screens. This strategy, while not typical, is also 
not that unusual, especially for movies targeting a more educated demographic, where the platforming strategy is often successfully employed. Obviously, first weekend grosses will underestimate total grosses when this strategy is employed.

\section{Foreign grosses}

Domestic grosses account for roughly $20 \%$ of a film's total revenue. Unfortunately, it is difficult to analyze foreign grosses, if for no other reason than movies are released in different countries over many months after release in the United States. In fact, some movies may be released abroad up to a year after the initial domestic U.S. release and continue to play abroad long after they have cycled through the various ancillary markets at home. To further complicate things, many times a movie is not released by the same distributor in any given market (rights are often sold by territory) making the tracking of these numbers more difficult. Some of the movies examined in this paper, for example, are still continuing to play at theaters around the globe at the time of this writing (autumn 1999).

It should be noted that certain films play better abroad than they do domestically, and that a studio is often aware of a given film's potential to fall into this category. For example, Stanley Kubrick's Eyes Wide Shut (released in 1999 by Warner Brothers with Tom Cruise and Nicole Kidman leading the cast) played better internationally than domestically, even though the stars were strong box office draws. The disturbing subject matter and long running time of the film were apparently reasons that kept U.S. audiences away, but were less likely to turn off foreign viewers. Additionally, films with big-name, big-salaried American actors like Sylvester Stallone and Kevin Costner can still 
command impressive revenues abroad, even though the actors are no longer box office gold at home. In recent years, international box office revenue has steadily gained in importance as compared to domestic box office revenue, to the point where international gross now accounts for approximately $60-70 \%$ of total box office gross.

We briefly examine forecasting foreign grosses in this section by examining grosses in the United Kingdom for the 67 films with U.S. gross over $\$ 25$ million that opened in the U.K. (out of 69 total). Instead of using first U.K. weekend gross, we will use total domestic (U.S.) gross as the "leading" predictor of U.K. gross. This is not quite right, since the movie has not necessarily closed in the U.S. when it opens in the U.K., but given the strong fit of the models fit earlier, it is reasonable to think that a studio would know the U.S. gross reasonably accurately by the time a movie opens in the U.K.

Figure 9 gives a scatter plot of Logged total U.K. gross (based on millions of pounds) versus Logged total U.S. gross. It is apparent that, generally speaking, movies that make more in the U.S. also make more in the U.K. The least squares regression line is superimposed on the plot; this is the final model, as no other variables add significant predictive power. The $\mathrm{R}^{2}$ of the model is only $50.6 \%$, demonstrating that many factors specific to the U.K. are unaccounted for. The standard error of the estimate is $s=.405$, which means that predictions are accurate to a multiplicative factor of roughly 6.5 (not very impressive, considering that the maximum total U.K. gross in the sample is only $£ 28.8$ million). Two outlying movies are identified: The Big Hit, a "Hong Kong action comedy" actually written by and starring Americans, which did more poorly than expected, and Spice World, the critically despised homage to the British pop group, which did better than expected. 


\section{Conclusion}

The analyses given here illustrate that the ultimate box office performance of movies can be forecast with some accuracy given easily available information. The predictions are especially accurate after the first weekend of release for movies opening on more than 10 screens, although the tendency for some distributors to slowly widen release of a film based on word of mouth complicates matters. Oscar nominations in the major categories do seem to provide a boost to revenues, as long as the movie has not already been in release for many months when the nominations are announced.

The models discussed here have certain limitations. It is quite possible that other predictors could improve the predictive power of the models. Two movies of the same type opening at the same time can result in reduced revenues for one or the other (or both) in the short run; does this effect carry over to long-run revenues? Clearly producers think so, since a great deal of thought goes into choosing release dates. It would also be interesting to see how much subsequent weeks' revenues add to predictive power over the first weekend grosses. A clearly important potential factor is the advertising budget for the film, but as was noted earlier, these figures are very difficult to obtain.

The focus here on domestic revenues ignores foreign grosses, which appear to be more difficult to predict. Other potentially important sources of revenue outside the theatre are also not considered here. These include home video, cable television, and network television, all of which could be important revenue streams to movie producers.

The surprise successes of 1998's There's Something About Mary and 1999's low, low budget thriller The Blair Witch Project demonstrate that even if a model performs 
well overall, the movie business is characterized by occasional films that defy expectations. "Since predicting gross is extremely difficult," comments Noonan, "you have to serve up a [yearly] slate of movies and know that over time you'll have 3 or 4 to the left and 2 or 3 to the right. You must make sure you are doing things that mitigate your downside risk."

\section{Acknowledgements}

The authors wish to thank Sam Craig, Dade Hayes, Leonard Klady, Tim Noonan, Ben Procter, and Joel Steckel for their invaluable contributions to this paper.

\section{Additional reading}

Dodds, J.C. and Holbrook, M.B. (1988), "What's an Oscar Worth? An empirical Estimation of the Effects of Nominations and Awards on Movie Distribution and Revenues," in Current Research in Film: Audiences, Economics, and Law, ed. B.A. Austin, Ablex Publishing Corp., Norwood, NJ, 72-88.

Eliashberg, J. and Shugan, S.M. (1997), "Film Critics: Influencers or Predictors?" Journal of Marketing, 61(2), 68-78.

Neelamegham, R. and Chintagunta, P. (1999), “A Bayesian Model to Forecast New Product Performance in Domestic and International Markets," Marketing Science, $18,115-136$.

Radas, S. and Shugan, S.M. (1998), "Seasonal Marketing and Timing New Product Introductions," Journal of Marketing Research, 35, 296-315. 
Ravid, S.A. (1999), "Information, Blockbusters and Stars - A Study of the Film Industry," Journal of Business, 72, 463-492.

Sawhney, M.S. and Eliashberg, J. (1996), “A Parsimonious Model For Forecasting Gross Box-Office Revenues of Motion Pictures," Marketing Science, 15, 113-131.

Wallace, W.T., Seigerman, A., and Holbrook, M.B. (1993), "The Role of Actors and Actresses in the Success of Films: How Much Is a Movie Star Worth," Journal of Cultural Economics, 17, 1-27. 
Table 1. Summary of model fitting using variables available before the release of a film.

\begin{tabular}{|c|c|c|c|c|}
\hline Variable & Effect & Coefficient & $\mathbf{F}$ & $\mathbf{p}$ \\
\hline Constant & & 0.394 & & \\
\hline \multirow{8}{*}{ Genre } & Action & 0.401 & 6.52 & .000 \\
\hline & Children's & -0.030 & & \\
\hline & Comedy & -0.189 & & \\
\hline & Documentary & -1.248 & & \\
\hline & Drama & -0.408 & & \\
\hline & Horror & 0.513 & & \\
\hline & Science Fiction & 0.693 & & \\
\hline & Thriller & 0.267 & & \\
\hline \multirow{6}{*}{ MPAA rating } & $\mathrm{G}$ & 0.534 & 9.49 & .000 \\
\hline & PG & 0.380 & & \\
\hline & PG-13 & 0.312 & & \\
\hline & $\mathrm{R}$ & -0.079 & & \\
\hline & NC-17 & -0.118 & & \\
\hline & $\mathrm{U}$ & -1.028 & & \\
\hline \multirow[t]{2}{*}{ Summer release } & No & -0.150 & 5.43 & .021 \\
\hline & Yes & 0.150 & & \\
\hline Best actors & & 0.400 & 13.15 & .000 \\
\hline Top dollar actors & & 0.712 & 20.61 & .000 \\
\hline & $\mathrm{R}^{2}=44.6 \%$ & $s=0.982$ & & \\
\hline
\end{tabular}


Table 2. Observed total domestic grosses and predicted grosses in millions of dollars based on three models for selected 1998 films.

\begin{tabular}{|c|c|c|c|c|}
\hline Movie & $\begin{array}{l}\text { Total } \\
\text { gross }\end{array}$ & $\begin{array}{l}\text { Prediction } \\
\text { (Pre- } \\
\text { release } \\
\text { model) }\end{array}$ & $\begin{array}{l}\text { Prediction } \\
\text { (First } \\
\text { weekend } \\
\text { model) }\end{array}$ & $\begin{array}{l}\text { Prediction } \\
\text { (Oscar } \\
\text { model) }\end{array}$ \\
\hline $\begin{array}{l}3 \text { Ninjas: High Moon at Mega } \\
\text { Mountain }\end{array}$ & 0.308 & 10.589 & 0.269 & 0.278 \\
\hline Air Bud: Golden Receiver & 10.215 & 11.183 & 6.354 & 6.416 \\
\hline Godzilla & 136.023 & 18.084 & 306.910 & 299.889 \\
\hline Good Will Hunting & 138.339 & 7.400 & 44.591 & 131.984 \\
\hline The Horse Whisperer & 75.370 & 1.405 & 63.932 & 59.391 \\
\hline Hurlyburly & 1.796 & 18.571 & 1.373 & 1.310 \\
\hline Saving Private Ryan & 216.119 & 14.791 & 194.622 & 358.237 \\
\hline Stepmom & 91.030 & 114.535 & 97.783 & 90.513 \\
\hline There's Something About Mary & 176.483 & 1.893 & 56.234 & 55.628 \\
\hline
\end{tabular}


Table 3. Summary of model fitting using variables available after the first weekend of release of a film.

(a) Movies opening on 10 or less screens

Variable Coefficient F p

Constant 2.509

$\begin{array}{llll}\text { Logged first weekend gross } & 1.808 & 242.70 & .000\end{array}$

$\begin{array}{llll}\text { Logged opening screens } & -0.539 & 8.14 \quad .005\end{array}$

$$
\mathrm{R}^{2}=73.5 \% \quad s=0.549
$$

(b) Movies opening on more than 10 screens

Variable

Constant

Genre

Logged first weekend gross

Logged opening screens

\section{Effect}

Action

Children's

Comedy

Documentary

Drama

Horror

Science Fiction

Thriller
Coefficient

1.983

$-0.054$

0.114

0.029

0.009

0.069

$-0.094$

$-0.047$

$-0.026$

1.525

$1160.36 \quad .000$

$-0.598$

$130.77 \quad .000$

$$
\mathrm{R}^{2}=96.6 \% \quad s=0.170
$$


Table 4. Summary of model fitting using variables available after the first weekend of release of a film and Oscar variables.

(a) Movies opening on 10 or less screens

$\begin{array}{lrcc}\text { Variable } & \text { Coefficient } & \text { F } & \text { p } \\ \text { Constant } & 2.392 & & \\ \text { Logged first weekend gross } & 1.756 & 235.64 & .000 \\ \text { Logged opening screens } & -0.537 & 8.53 & .004 \\ \text { Oscar nominations } & 0.409 & 7.57 & .007 \\ & & & \\ \qquad \mathrm{R}^{2}=75.1 \% \quad s=0.534\end{array}$

(b) Movies opening on more than 10 screens

Variable

Constant

Genre

Logged first weekend gross

Logged opening screens

Oscar nominations

\section{Effect}

Action

Children's

Comedy

Documentary

Drama

Horror

Science Fiction

Thriller

\section{Coefficient}

1.961

$-0.048$

0.118

0.031

0.006

0.047

$-0.090$

$-0.041$

$-0.023$

1.512

$1209.77 \quad .000$

$-0.590$

$135.49 \quad .000$

0.100

$$
\mathrm{R}^{2}=96.8 \% \quad s=0.165
$$


Figure 1: Side-by-side boxplots of Total domestic gross in millions of dollars separated by levels of variables available before the release of a film.
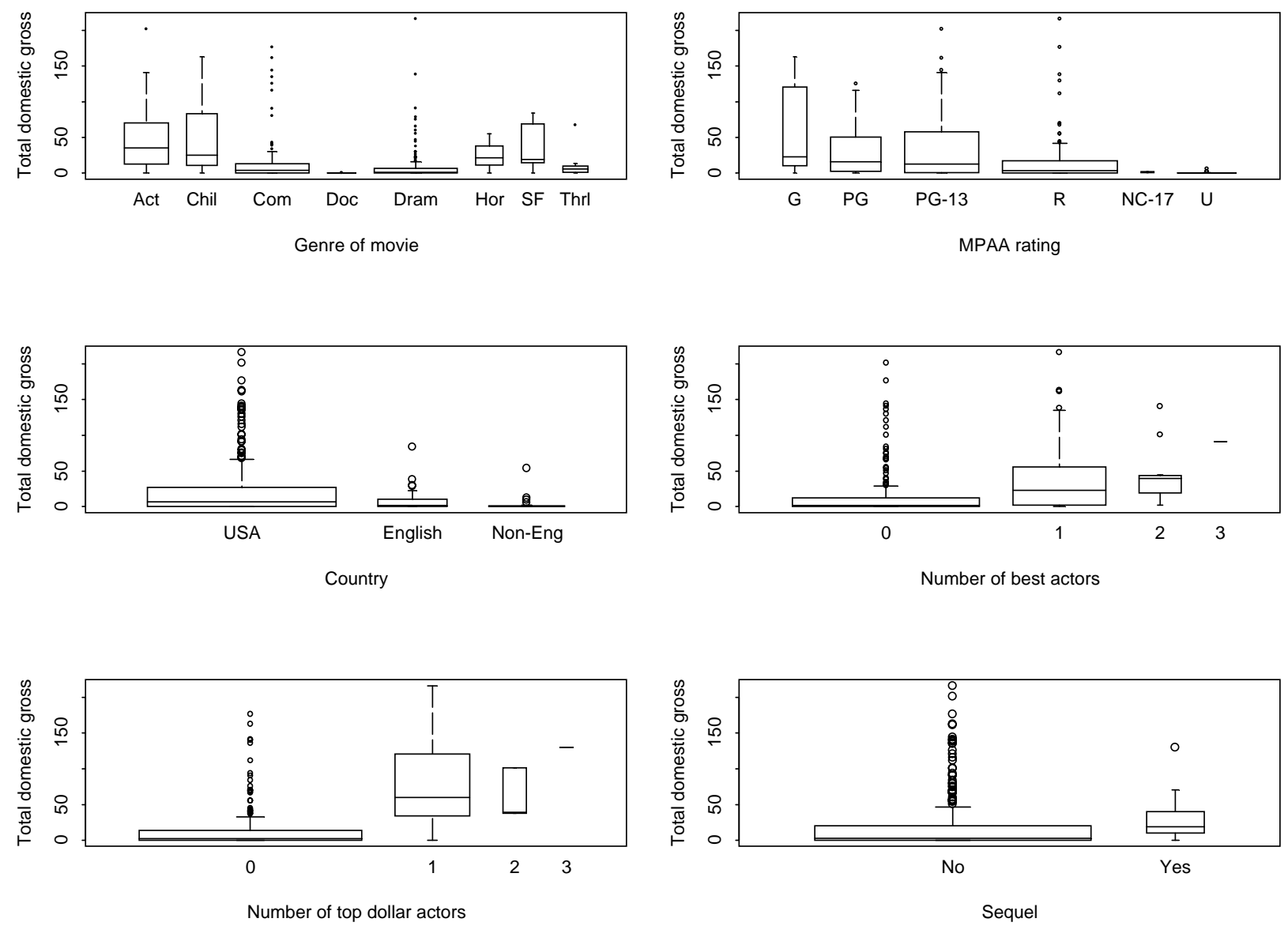

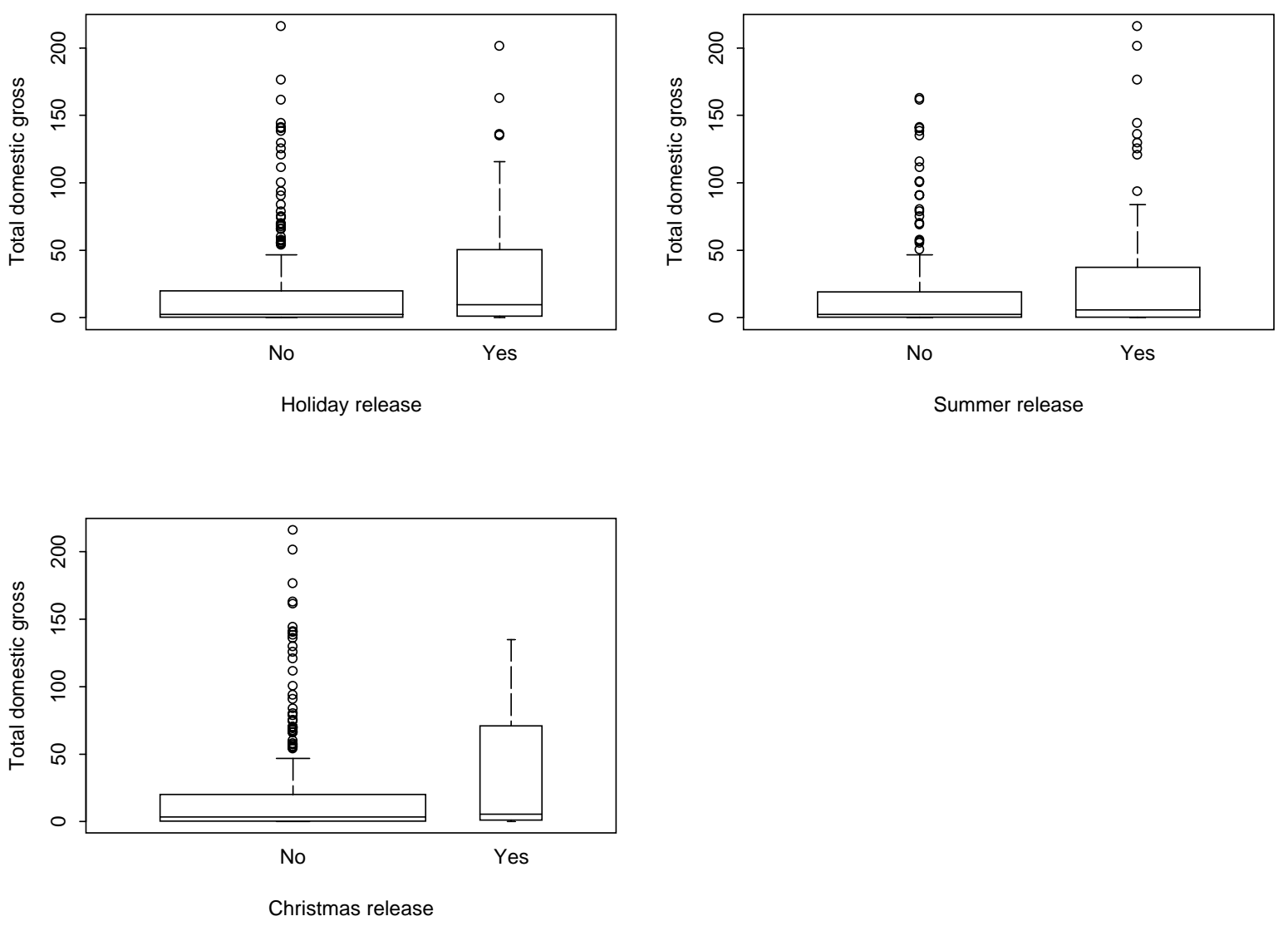
Figure 2. Scatter plot of Logged total domestic gross versus Logged budget.

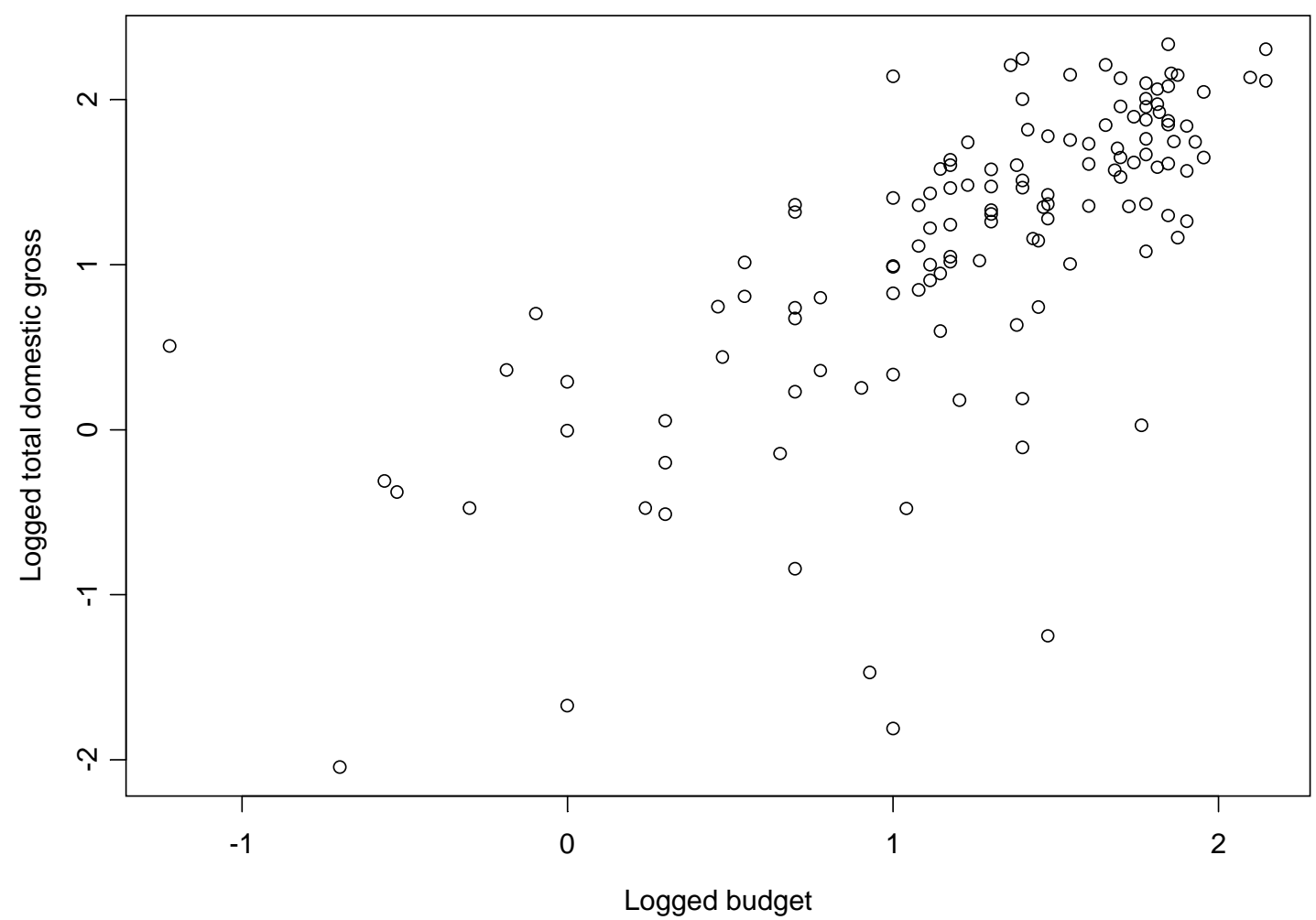


Figure 3. Scatter plot of Logged total domestic gross versus Logged first weekend gross.

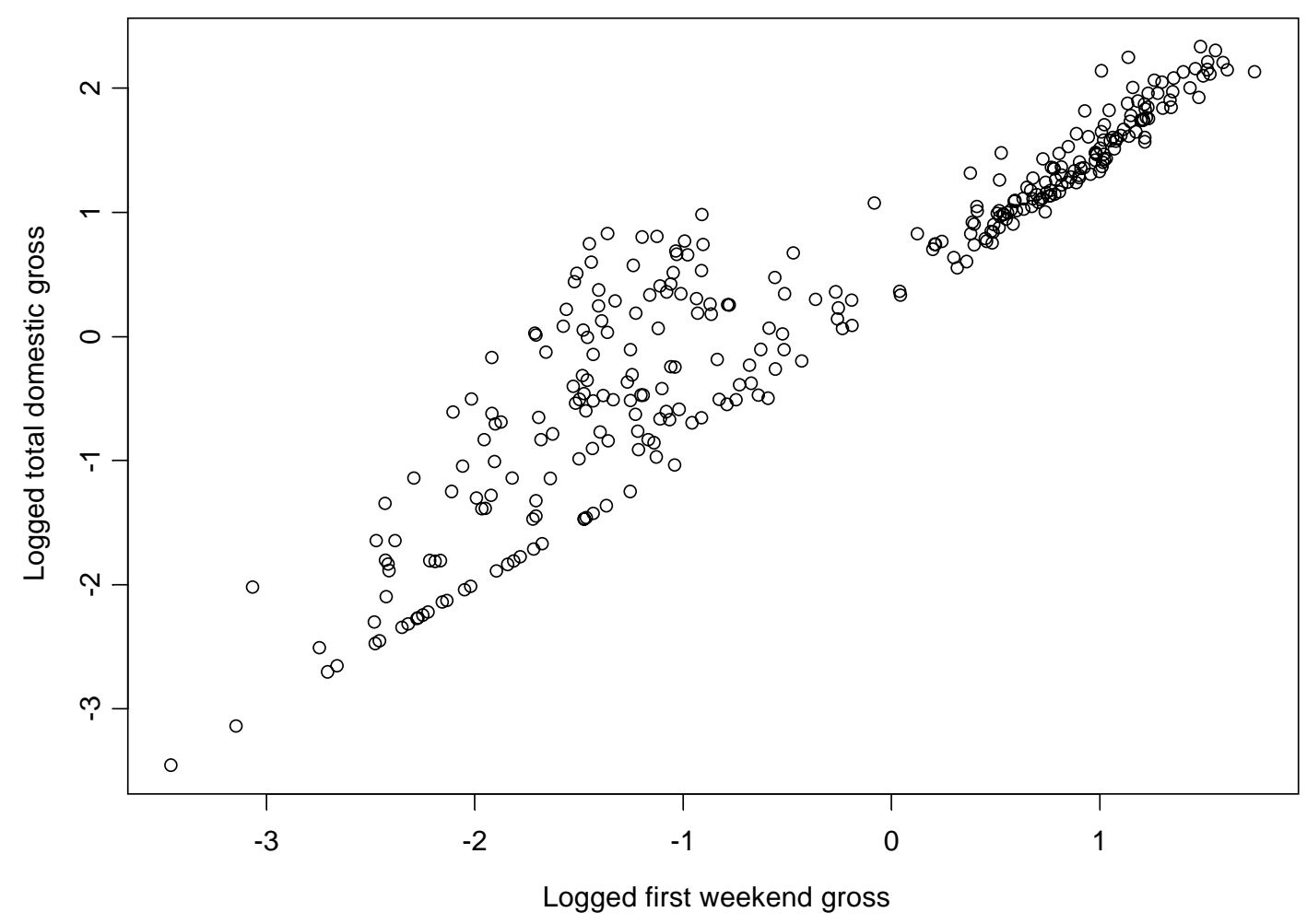


Figure 4. Scatter plot of Standardized residuals versus Logged first weekend gross for model using Genre, Logged first weekend gross, and Logged opening screens as predictors.

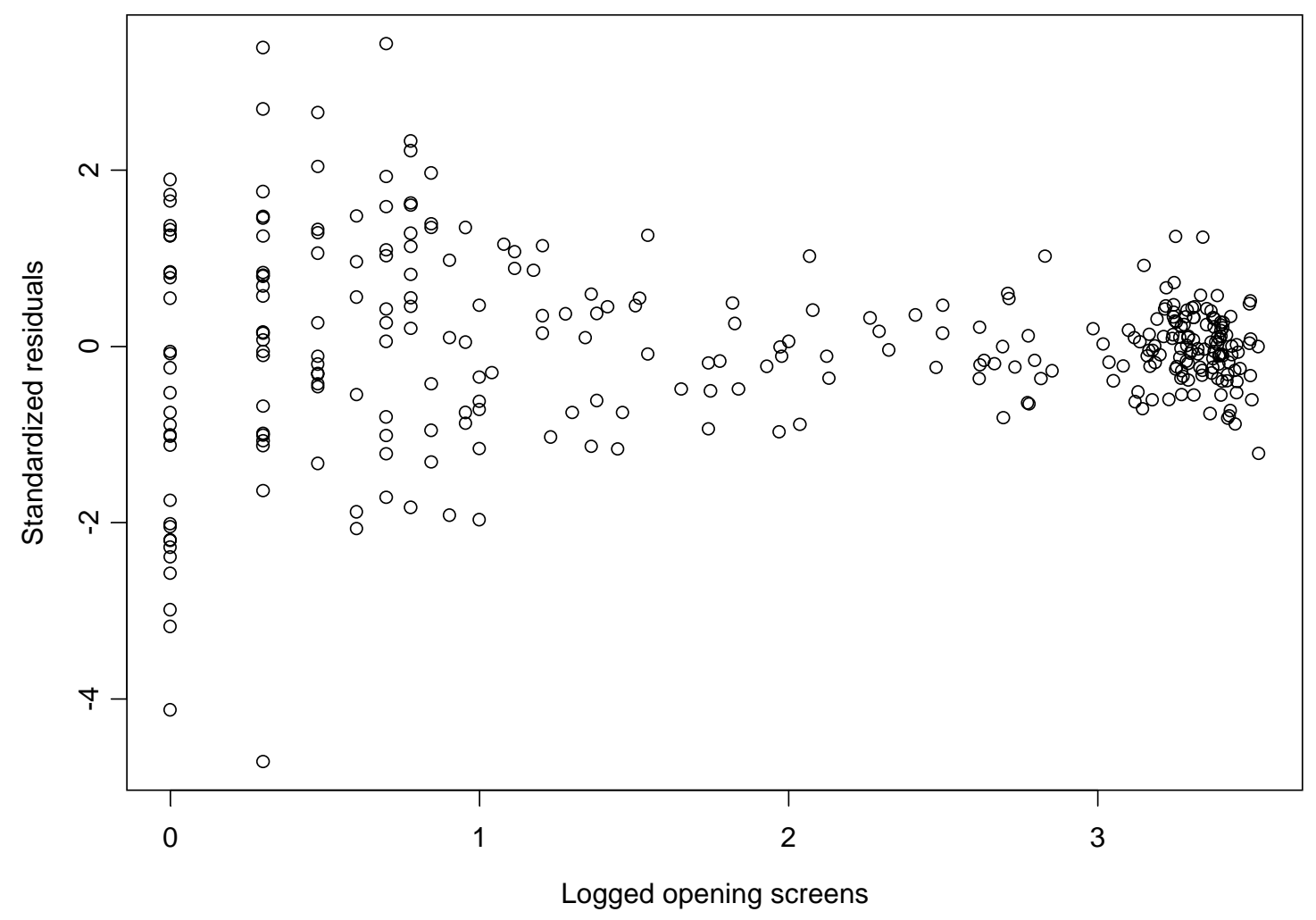


Figure 5. Scatter plot of Logged total domestic gross versus Logged first weekend gross, with movies labeled by whether they opened on 10 screens or less (pluses) or more than 10 screens (circles).

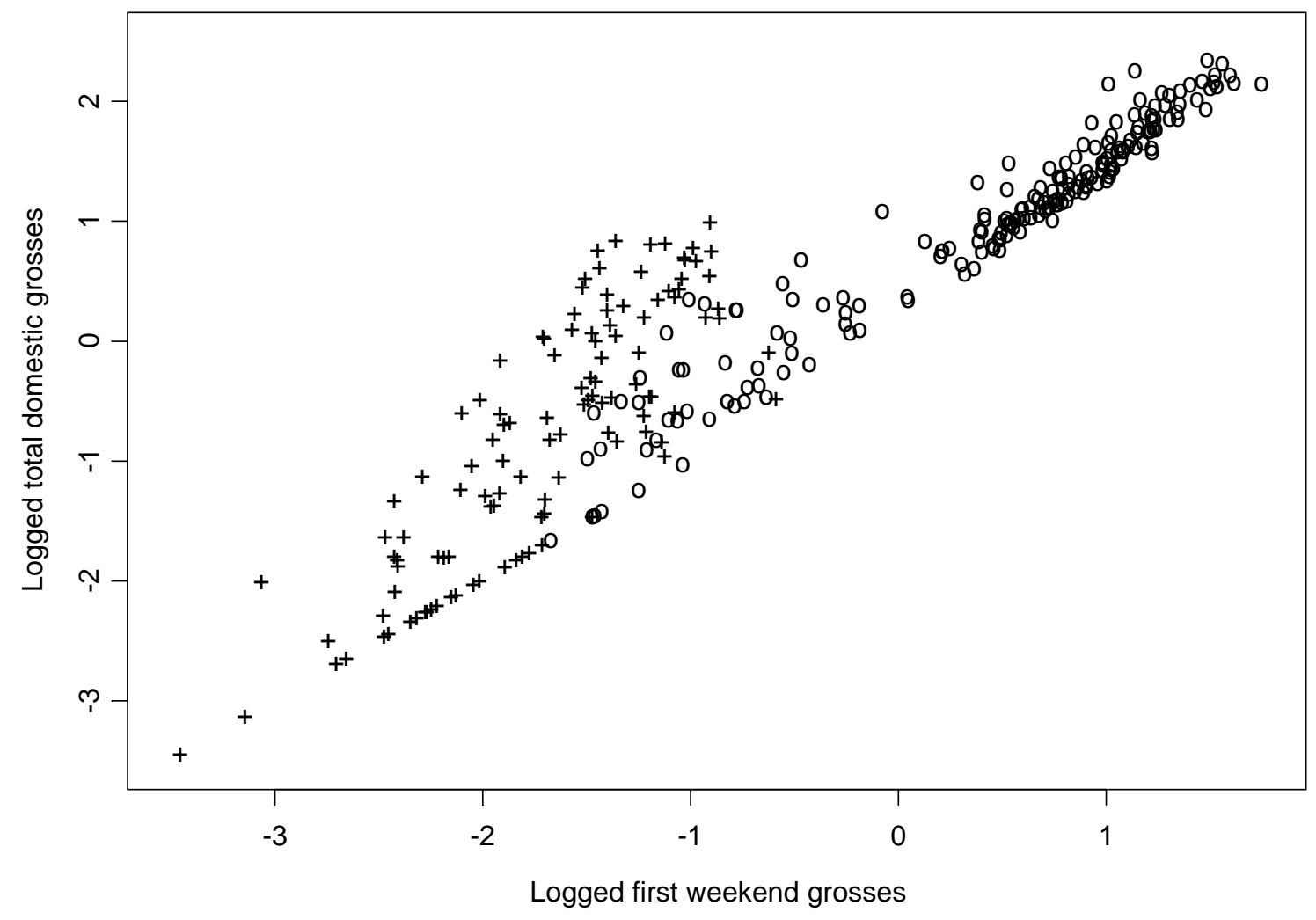


Figure 6. Scatter plot of standardized residuals versus fitted values for model on films that opened on 10 or less opening screens.

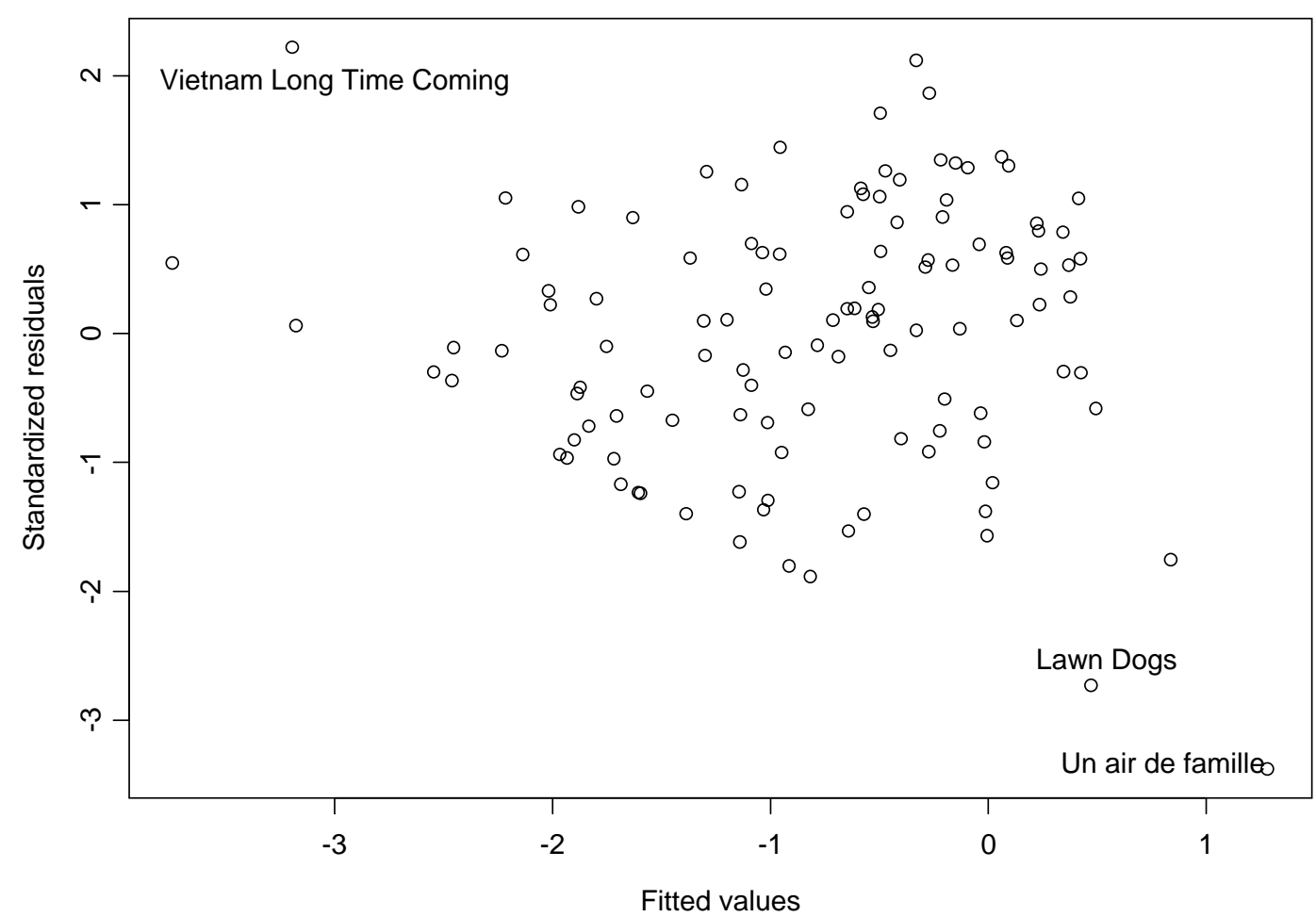


Figure 7. Scatter plots of absolute standardized residuals for model using Oscar nominations versus model not using Oscar nominations, for (a) movies released on at most ten screens, and (b) movies released on more than ten screens. Movies that received major Oscar nominations are noted on the plots.

(a)

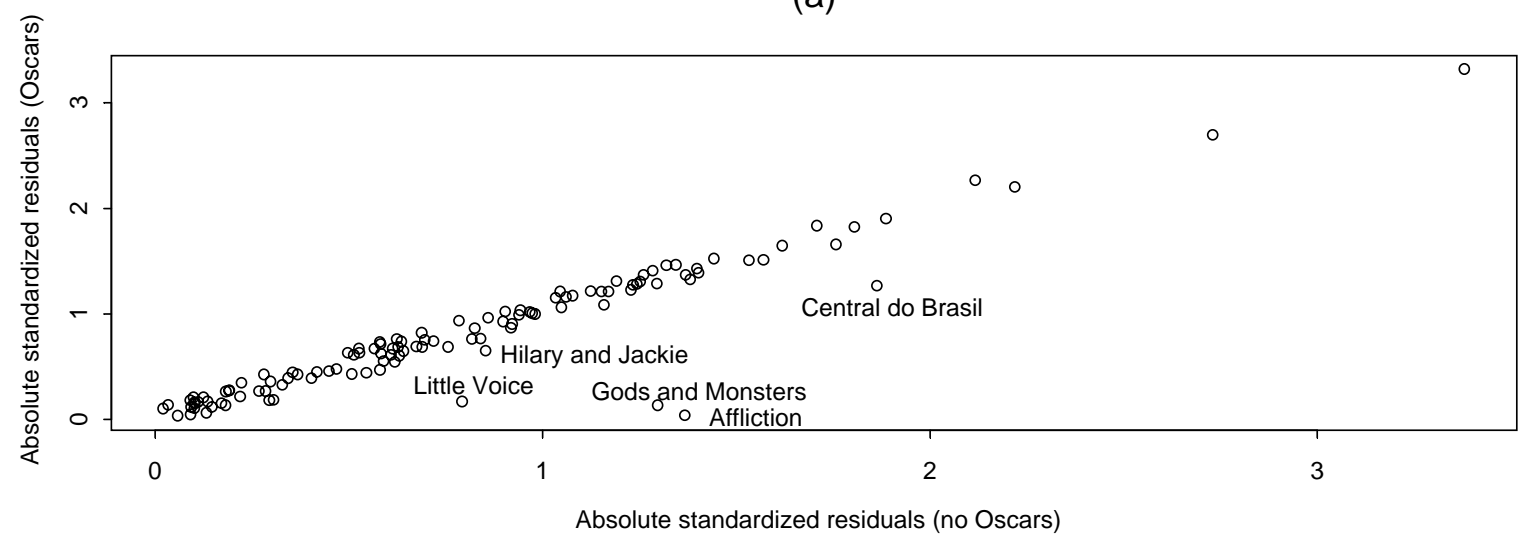

(b)

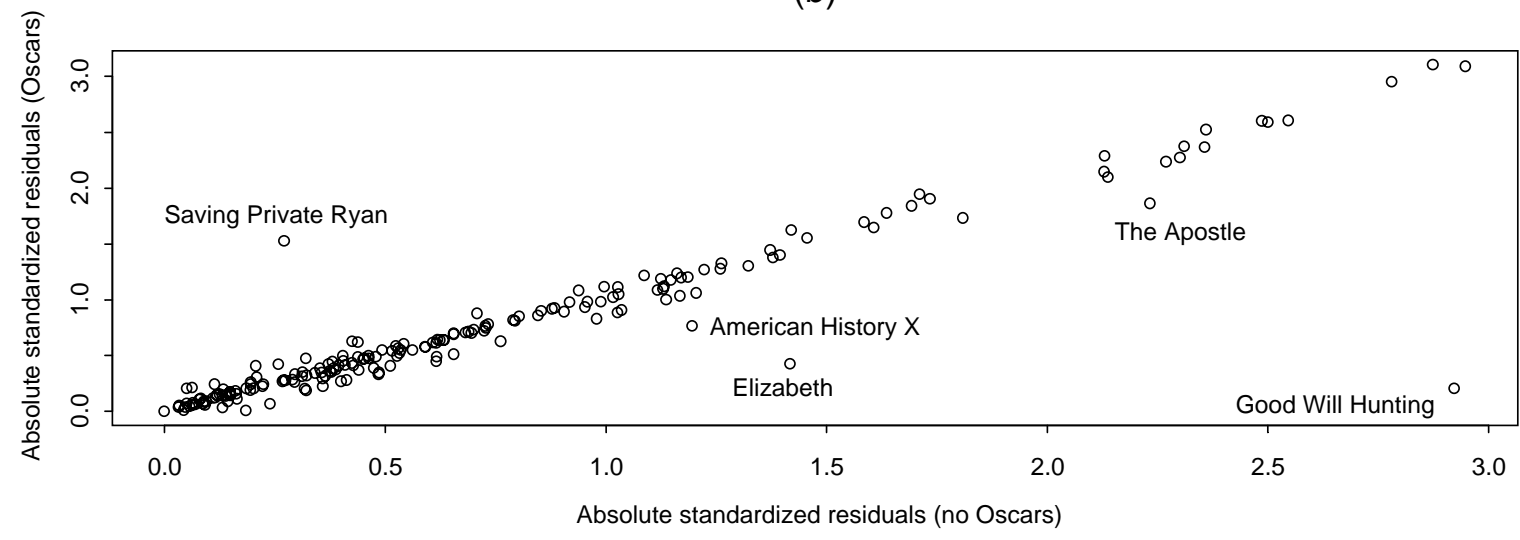


Figure 8. Predicted and observed total grosses for films released in early 1999. Predicted grosses are marked with "x," observed grosses are marked with "o," and prediction intervals are given by "( )."
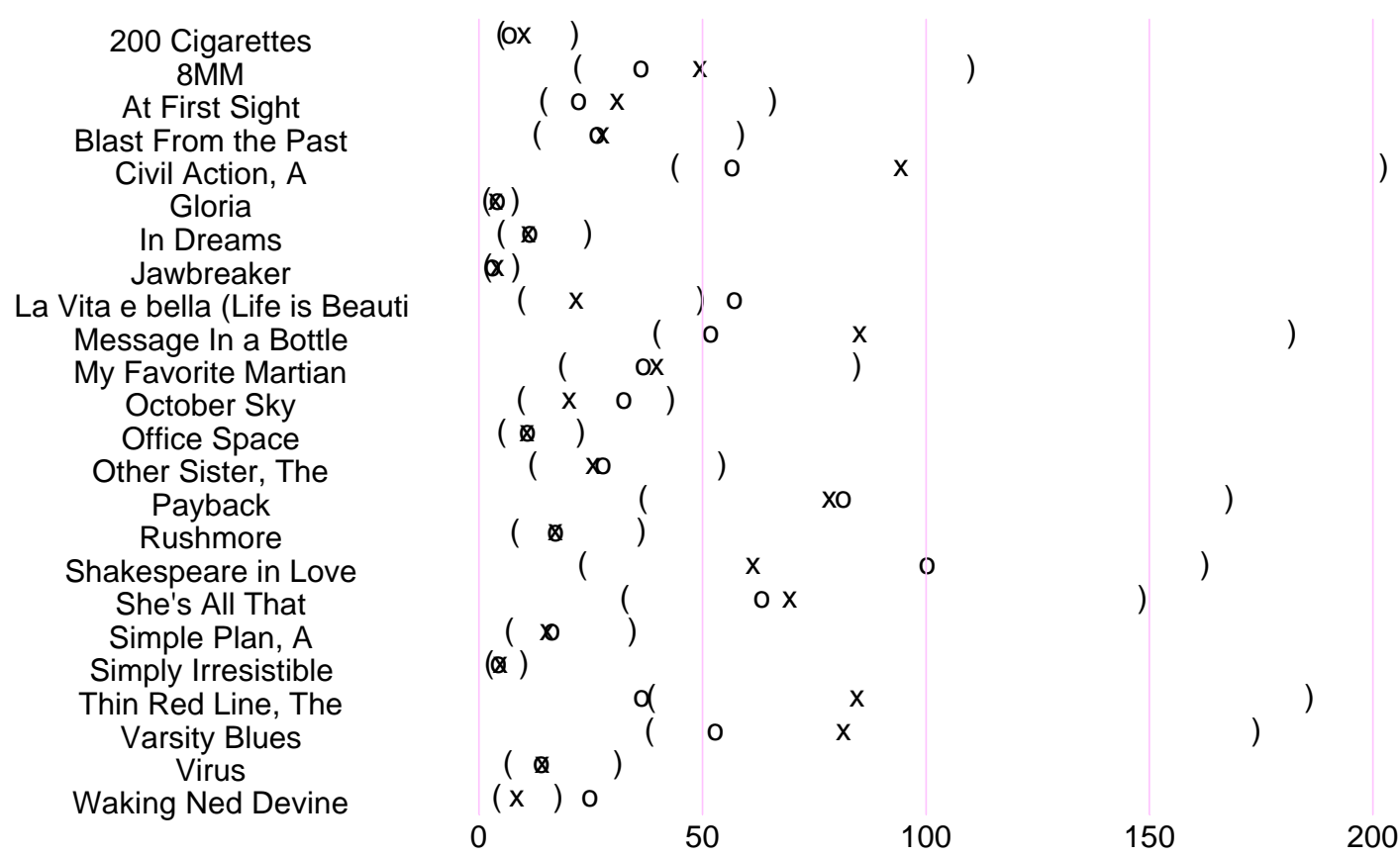

Total domestic gross 
Figure 9. Scatter plot of Logged total U.K. gross versus Logged total U.S. gross. The least squares regression line is superimposed on the plot, and two unusual movies are identified.

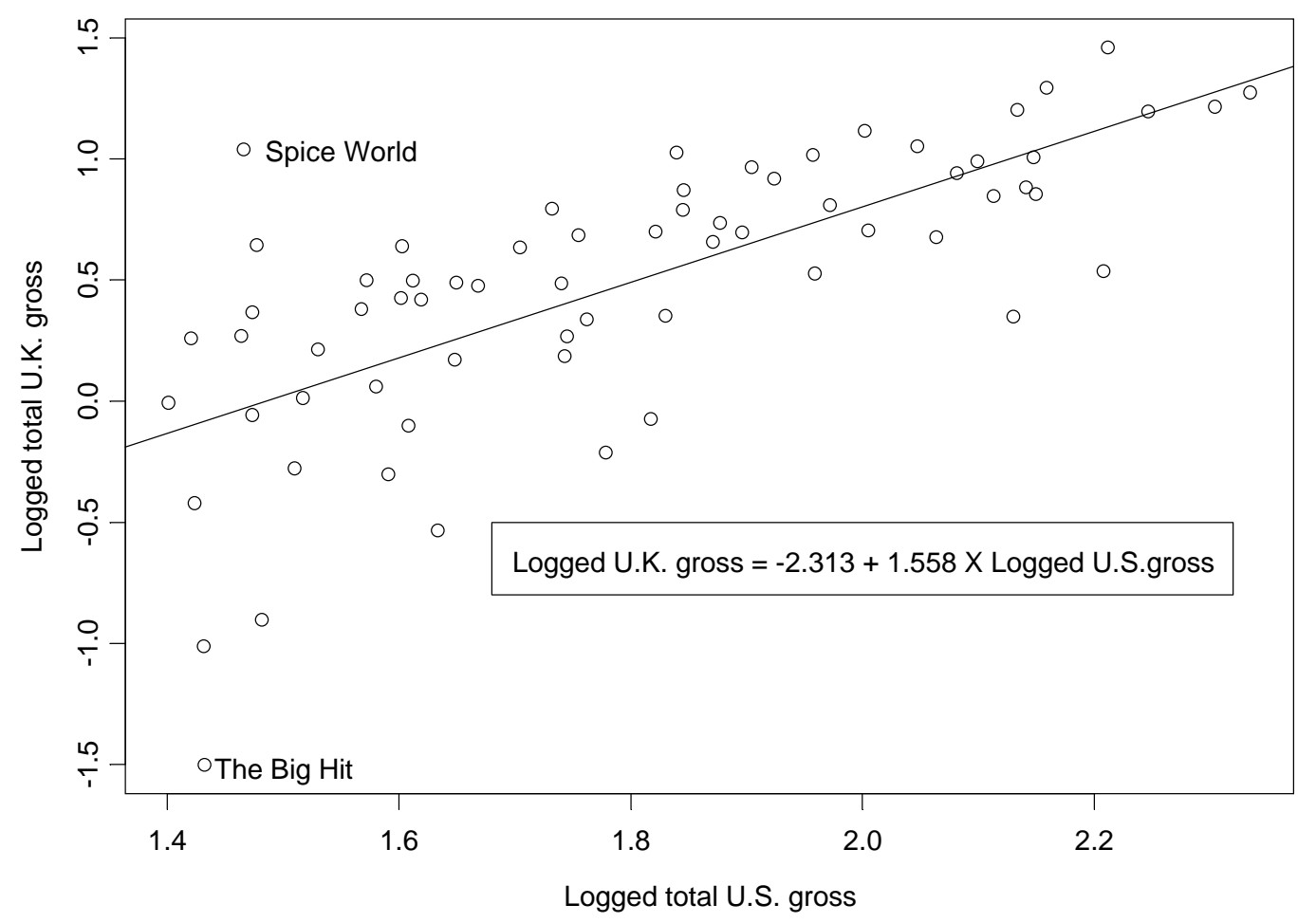

